\title{
Profile of scald injury among Paediatrics patient attending tertiary care hospital
}

\author{
S Prabakaran ${ }^{1}$ \\ ${ }^{1}$ Dr. S Prabakaran, Department of Paediatric Surgery, Govt Mohan Kumara Mangalam Medical College \& Hospital, \\ Salem, Tamil Nadu, India. \\ Corresponding Author: Dr. S Prabakaran, Department of Paediatric Surgery, Govt Mohan Kumara Mangalam Medical \\ College \& Hospital, Salem, Tamil Nadu, India. Email: paedprabakaran@gmail.com
}

\begin{abstract}
Background: Scald injuries among children are a significant cause of mortality and morbidity. This is compounded by the additional risk factors such as poverty, higher birth order and urban slums which are seen in developing countries. But very few studies are available regarding the burden of this issue. This study seeks to assess the same. Methods: A prospective observational study was conducted in a tertiary care hospital for one year.A total of 66 children less than 12 years of age were included. Their demographic profile and treatment outcome were studied. Results: Most participants were less than 10 years old and almost half had first degree burns. Hot water scalds were the most common etiology followed by household liquid foods such as sambar and kanji. Most burns affected the front of the body. Silver nitrodiazine was the most common treatment followed by collagen application and open dressing. After treatment $81.5 \%$ improved. The mortality was $16.7 \%$. Conclusions: Scald injuries are a common cause of morbidity among young children. Most incidents occur at home and are preventable. This indicates the need for parental education and the child safety measures for reducing mortality and morbidity due to scalds.
\end{abstract}

Keywords: Scalds, Burns, Paediatric-injuries

\section{Introduction}

Scald injuries are an issue of significant public health importance. It is also one of the major contributors of significant mortality and morbidity in the world [1]. It has multiple adverse sequelae such as pain and a protracted duration of treatment which may extend up to a life time in some instances. Approximately onethird to a half of all the burn injuries among high- and middle-income countries are due to scalds and $5 \%$ of all the deaths due to burn are scald injuries $[2,3]$.

Although the incidence of burn injuries has considerably declined in the developed countries, there is still a need for information regarding the epidemiology of burn injuries and the potential risk factors. Children in the pre-school age experience a higher proportion of mortality when compared to other age groups. The mortality rate due to scald injuries among children under 4 years of age was $46.9 \%$. The mortality reported in the current study was much higher than the reported mortality of $12.9 \%$ among older children reported by a previous study [2]

Manuscript received: $30^{\text {th }}$ June 2018

Reviewed: $9^{\text {th }}$ July 2018

Author Corrected: $17^{\text {th }}$ July 2018

Accepted for Publication: $21^{\text {st }}$ July 2018
Scald injuries have multiple economic consequences as well. In a report by Miller et al observed that scald injuries and deaths among children less than 14 years of age alone account for $\$ 2.1$ billion dollars expenses in the United States each year [3]. In a report by the British Burns Association, a case of serious bath water scald on intensive treatment would cause an expenditure of $\$ 280,000$ [4].

Various studies have been conducted regarding the risk factors for injuries among children. A study by Bijur P et al identified problem drinking among mothers and problem drinking among both parents to be associated with an increased risk of injuries [5]. Other factors such as male gender, deprived urban neighborhood, number of older siblings and increased distance from the hospital were also found to be risk factors for scald injuries among children [6]. A study by Shah et al (2013) identified that the risk for scald injuries was greatest at 13 to 24 months of age compared to older children [1]. This is probably due to the fact that preschool children are more dependent on their mothers while at home [7]. Previous history of perinatal depression was also found to be a risk factor for scald 


\section{Original Research Article}

injuries among children [1]. Since majority of the scald injuries occur at home, the etiology are mostly household items. Earlier in developed countries, tap water at high temperature was the commonest etiology of scald injuries [8]. But the profile has changed in recent times, to include other causes as well. In a study by Agbenorku et al found that hot water was the commonest cause of scald injuries among children amounting to $68.1 \%$. Other factors were hot soup (15.6\%), hot tea (4.3\%), hot oil $(9.2 \%)$, hot stew $(9.7 \%)$ and hot stock (2.1\%)[9].

Despite the vast information available on scald injuries in the pediatric age group, very few studies have been done in developing countries such as India. Knowledge of the epidemiology of pediatric scald injuries will enable the planning of appropriate preventive measures. These may include parental education, identifying the households at risk and implementation of child safety measures. This study seeks to assess the burden of scald injuries and the associated factors.

\section{Objectives}

1. To analyze the demographic and clinical profile of scald injuries presenting to a tertiary care teaching hospital

2. To analyze the treatments procedures done and the treatment outcome in pediatric patients presenting with scald injuries.

\section{Methods}

Place of study: Department of Paediatric surgery in a tertiary care teaching hospital

Type of study: Prospective observational study
Study population: Children presenting with scald injuries to the study setting

Sampling methods: All the study subjects were selected in to the study sequentially

Data collection period: The data collection for the study was done between January to December 2017, for a period of 12 months

\section{Inclusion criteria}

- Children below 12 years,

- Both genders,

- presenting or referred to the study setting with scald injuries

\section{Exclusion criteria}

- Children aged More than 12

- Children with mixed burn injuries

Statistical methods: Descriptive analysis was carried out by mean and standard deviation for quantitative variables, frequency and proportion for categorical variables. $\mathrm{P}$ value $<0.05$ was considered statistically significant. IBM SPSS version 22 was used for statistical analysis [10].

Demographic parameters like (age, gender), severity, agent, BSA (\%), BSA (\%) group, methods (silvernitrodizaine cream local application, collage application, open dressing, closed dressing), side involved front, site involved, side involved back, site involved, final outcome participants were considered as the outcome variables of interest.

\section{Results}

A total 66 people participants were included in the analysis. The mean age was $54.09 \pm 38.4$ in the study population, minimum age was 9 months and maximum age was 144 months.

Table-1: Descriptive analysis of demographic parameter in study population $(\mathrm{N}=66)$.

\begin{tabular}{|c|c|c|}
\hline Demographic parameter & Frequency & Percentages \\
\hline \multicolumn{3}{|c|}{ Age group (in year) } \\
\hline below 1 year & 3 & $4.50 \%$ \\
\hline 1 to 2 years & 22 & $33.30 \%$ \\
\hline 3 to 5 years & 17 & $25.80 \%$ \\
\hline 6 to 10 years & 19 & $28.80 \%$ \\
\hline Above 10 years & 4 & $6.10 \%$ \\
\hline Male & Gender \\
\hline Female & 31 & $47.00 \%$ \\
\hline
\end{tabular}




\section{Original Research Article}

Among the study population, $3(4.50 \%)$ participants were aged below 1 year, $22(33.30 \%)$ participants were aged between 1 to 2 years, $17(25.80 \%)$ participants were aged between 3 to 5 years, $19(28.80 \%)$ participants were aged between 6 to 10 years and $4(6.10 \%)$ participants were aged above 10 years. Among the study population, 31(47\%) participants were male, and remaining 35 (53\%) participants were female. (Table 1)

Table- 2: Descriptive analysis of severity in study population $(\mathrm{N}=66)$

\begin{tabular}{|c|c|}
\hline Parameter & Summary \\
\hline \multicolumn{2}{|c|}{ Severity } \\
\hline $1^{\circ}$ & $38(57.5 \%)$ \\
\hline $2^{\circ}$ & $23(34.8 \%)$ \\
\hline $2^{\circ}$ deep and $3^{\circ}$ & $3(4.54 \%)$ \\
\hline \multicolumn{2}{|c|}{ Agent } \\
\hline Hot water & $24(36.36 \%)$ \\
\hline Hot tea & $10(15.15 \%)$ \\
\hline Hot sambar & $7(10.60 \%)$ \\
\hline Hot flame & $18(27.27 \%)$ \\
\hline Hot Kanji & $7(10.60 \%)$ \\
\hline \multicolumn{2}{|c|}{ BSA (\%) group } \\
\hline Less than 10 & $17(25.80 \%)$ \\
\hline 11 to 30 & $34(51.50 \%)$ \\
\hline 31 to 50 & $7(10.60 \%)$ \\
\hline 51 and above & $8(12.10 \%)$ \\
\hline
\end{tabular}

Among the study population, $38(57.5 \%)$ participants had severity of $1^{\circ}, 23(34.8 \%)$ participant had severity of $2^{\circ}$ and 3 (4.54\%) participant had $2^{\circ}$ deep and $3^{\circ}$. Among the study population, in 24(36.36\%) participants the cause of scald injury was hot water, in $10(15.15 \%)$ subjects it was hot tea, in $7(10.60 \%)$ it was "Sambar".

The number of children injured by hot flame and hot "kanji" were 18 (27.27\%) and 7 (10.60\%) respectively. Among the study population, $17(25.80 \%)$ participants had less than $10 \%$ of body surface area, 34(51.50\%) participants had 11 to $30 \%$ of body surface area, $7(10.60 \%)$ participants had 31 to $50 \%$ of body surface area, and $8(12.10 \%)$ participants had $51 \%$ and above. (Table 2)

Table-3: Descriptive analysis of front in study population $(\mathrm{N}=66)$.

\begin{tabular}{|c|c|c|}
\hline Front & Frequency & Percent \\
\hline Side involved front & 63 & $95.50 \%$ \\
\hline \multicolumn{3}{|c|}{ Site involved } \\
\hline Abdomen & 23 & $34.80 \%$ \\
\hline Face & 11 & $16.70 \%$ \\
\hline Chest & 22 & $33.30 \%$ \\
\hline Upper limb & 29 & $43.90 \%$ \\
\hline Lower limb & 20 & $30.30 \%$ \\
\hline Perineum & 13 & $19.70 \%$ \\
\hline Side involved back & Back & $27.30 \%$ \\
\hline Head & 18 & $3.00 \%$ \\
\hline Chest & Site involved & $13.60 \%$ \\
\hline Upper limb & 2 & $10.60 \%$ \\
\hline Lower limb & 9 & $12.10 \%$ \\
\hline Perineum & 7 & $15.20 \%$ \\
\hline Abdomen & 8 & $12.10 \%$ \\
\hline
\end{tabular}


Among the study population, 63(95.50\%) participants were affected infront side involved, 23(34.80\%) participants were affected in abdomen, 11(16.70\%) participants were affected in face, 22(33.30\%) participants were affected in chest, 29 (43.90\%) participants were affected in upper limb, 20(30.30\%) participants were affected in lower limb and 13(19.70\%) participants were affected in perineum. Among the study population, $18(27.30 \%)$ participants were affected in back side involved, $2(3 \%)$ participants were affected in head, $9(13.60 \%)$ participants were affected in chest, $7(10.60 \%)$ participants were affected in upper limp, $8(12.10 \%)$ participants were affected in lower limb, $10(15.20 \%)$ participants were affected in perineum and $8(12.10 \%)$ participants were affected in abdomen. (Table 3)

Table-4: Descriptive analysis of method and final outcome in study population ( $N=66)$.

\begin{tabular}{|c|c|c|}
\hline Methods & Frequency & Percentages \\
\hline Silvernitrodizaine cream local application & 46 & $69.70 \%$ \\
\hline Collagen application & 20 & $30.30 \%$ \\
\hline Open dressing & 14 & $21.20 \%$ \\
\hline Closed dressing & 1 & $1.50 \%$ \\
\hline \multicolumn{2}{|c|}{} \\
\hline Improved & 54 & $81.80 \%$ \\
\hline Discharge & 1 & $1.50 \%$ \\
\hline Expired & 11 & $16.70 \%$ \\
\hline
\end{tabular}

Among the study population, 46(69.70\%) participants had silvernitrodizaine cream local application, 20(30.30\%) had collagen application, $14(21.20 \%)$ had open dressing and $1(1.50 \%)$ had Closed dressing. Among the study population, 54 $(81.80 \%)$ participants had improved, $1(1.50 \%)$ participants had discharge, and $11(16.70 \%)$ participants had expired (Table 4).

\section{Discussion}

Socio-demographic profile of the study participants: Almost three-fourths of the participants belonged to the age group of 13 months to 120 months. The mean age was 54.09 months. The mean age is similar to the study by Palmieri T. L et al (57.6 months) and is higher than in the study by Rimmer RB et al (20.7 months) and Agbenorkuet al (26.16 months). The mean age is slightly lesser than the mean age in the study by Yeoh et al (1994) where the mean age was 40.14 months [9, 1113].

There was a slightly higher proportion of females (53\%) compared to males $(47 \%)$ in the study population. The male:female ratio was 1:0.88. The gender distribution is similar to the study by Palmieri T. L et al where the male: female ratio was 1:0.96. The male: female ratio is lesser than in the studies by Shah et al(1.22:1), Rimmer RB et al (1.08.1), Yeoh et al (1.19:1) and Agbenorku et al (1.23:1). The proportions of males were higher in these studies compared to females $[1,9,11,12,13]$.

Etiologic agents of scald injuries: With regards to the etiologic agents of scald injuries, similar to other studies, hot water is the most common cause [8, 9, 14]. In developed countries, bath water scald injuries were more common while in this study, scald injuries in the kitchen were more common. This was similar to the study by Delgado et al who mention that kitchen is a common site for occurrence of pediatric scald injuries [14]. Household liquid food items such as sambar and kanji were some of the etiologic agents of scalds. Furthermore, there were no reported cases of scalds due to non-accidental causes in this study $[1,11,15]$.

Body surface area affected by scalds: The mean body surface area affected by burns in this study was $26.8 \pm$ $19.99 \%$. This is much higher than the estimate by Morrow et al where the mean body surface area affected by scalds was $15.1 \pm 0.7 \%$. Rimmer et al estimated the mean body surface area affected to be $8 \%$ in their study while Millan et al (2012) estimated it to be $10 \%$. Marashi et al estimated the mean body surface area affected by burns in their study to be $12.29 \% \pm 21.18 \%$ $[2,13,15,16]$. This indicates that the pattern of pediatric scald injuries among the developing countries like India are much different from those in the developed countries. A greater percentage of body surface area is affected by scald injuries compared to results from studies conducted in developed countries.

The upper limb especially in the front was the most common site of involvement in this study. The findings 
are similar to the study by Millan et al where the upper limb was involved in $54.1 \%$ area. Involvement of Head and neck along with trunk are lesser in the current study compared to Milan et al. Head and neck was involved in $46.9 \%$ in the study by Milan et al compared to $16.7 \%$ \& $3 \%$ in the anterior and posterior aspect respectively in this current study. The involvement of trunk was slightly higher according to Milan at al estimated to be at $45.9 \%$. In this study $33.3 \%$ of anterior aspect and $25.7 \%$ of posterior aspects were involved. A greater percentage of body surface area in lower limb and perineum was involved in the current study estimated at $50 \%$ \& $27.30 \%$ in the front and back respectively. This is higher than the $33.7 \%$ estimated by Millan et al[15].

Treatment outcomes of pediatric scale injuries: More than half the participants had first degree burns and mostly were managed by local application of silver nitrodiazine cream. Collagen application was used in $30.30 \%$ of the participants, $21.20 \%$ were managed by open dressing and $1.5 \%$ were managed by closed dressing. The type of management was similar to the study by Millan et al (2012) who mention that $41.8 \%$ were managed by topical application and dressing. The rest of the participants needed further surgical management.

When the final outcome was observed, $81.8 \%$ of the participants improved. $1.5 \%$ were discharged while $16.7 \%$ expired. The mortality was higher than the study by Yeoh et al, where the mortality rate was $1.47 \%$ and Morrow et al (1996) with mortality rate of $4.7 \%$ and Agbenorku et al, where the mortality rate was $9.2 \%[2$, $9,11]$. Compared to other studies, the current study has a higher mortality among pediatric patients with scald injuries. This may be due to the fact that a high proportion of patients $(22.7 \%)$ had burn injuries affecting $30 \%$ or above of the body surface area. Burns affecting $30 \%$ or more of the BSA has been found to be associated with an increased risk of mortality [9].

With regards to morbidity, this study had a higher proportion of discharged or improved patients (83.3\%) compared to the studies by Yeoh et al (1994) where the discharge rate was $53.1 \%$ and Agbenorku et al where $58.9 \%$ of the patients were discharged $[9,11]$.

\section{Conclusion}

A majority of the scald injuries occur in children who are less than 10 years of age with more than half occurring in the under 5 age group. More than half were first degree burns with majority affecting the front of the body. The common etiologies were hot water and other hot edible items. The etiologic agents of pediatric scald injuries are different from those found in the studies conducted in developing countries. Despite treatment, $16.7 \%$ expired. Kitchen is the most common site of occurrence of scalds. This necessitates childhood safety measures and health education to the mothers and care givers of the child regarding preventive measures.

In addition, this study provides scope for further studies to assess the risk factors for this increase in mortality. This would help in reducing the morbidity and mortality from scald injuries in the pediatric age group.

\section{Addition of new knowledge}

- Liquid food items are the most common sources of pediatric scald injuries

- Majority of scald injuries occurs in children less than 5 years of age

- Front of the body especially the upper limbs are commonly affected areas

- A higher proportion of patients have more than $30 \%$ BSA affected by burns compared to other studies, in addition to a higher mortality rate due to scalds

Author contribution: Dr.S. Prabakaranis the only author, who has conceptualized the study, conducted data collection, prepared and reviewed all the drafts and had prepared the final version of the manuscript.

\section{Declarations}

Funding: Nil, Conflict of interest: None initiated, Perission from IRB: Yes

Ethical approval: the study was approved by the institutional human ethics committee

\section{References}

1. Shah M, Orton E, Tata LJ, Gomes C, Kendrick D. Risk factors for scald injury in children under 5 years of age: A case-control study using routinely collected data. Burns. 2013 2013/11/01/; 39(7):1474-8.

2. Morrow SE, Smith DL, Cairns BA, Howell PD, Nakayama DK, Peterson HD. Etiology and outcome of pediatric burns. J Pediatr Surg. 1996 Mar;31(3):329-33.

3. Miller TR, Romano EO, Spicer RS. The cost of childhood unintentional injuries and the value of prevention. Future Child. 2000;10(1):137-63.

4. Gillam S, Abbott S, Banks-Smith J. Can primary care groups and trusts improve health? BMJ. 2001 Jul;323 (7304): 89-92. 


\section{Original Research Article}

5. Bijur PE, Kurzon M, Overpeck MD, Scheidt PC. Parental alcohol use, problem drinking, and children's injuries. JAMA. 1992 Jun;267(23):3166-71.

6. Reading R, Langford IH, Haynes R, Lovett A. Accidents to preschool children: comparing family and neighbourhood risk factors. Social Science \& Medicine. 1999 1999/02/01/;48(3):321-30.

7. Hatamabadi HR, Mahfoozpour S, Alimohammadi H, Younesian S. Evaluation of factors influencing knowledge and attitudes of mothers with preschool children regarding their adoption of preventive measures for home injuries referred to academic emergency centres, Tehran, Iran. Int J Inj Contr Saf Promot. 2014;21 (3):252-9.

8. Feldman KW, Schaller RT, Feldman JA, McMillon M. Tap water scald burns in children. 1997. Inj Prev. 1998 Sep;4(3):238-42.

9. Agbenorku P. Early childhood severe scalds in a developing country: A 3-year retrospective study. Burns \& Trauma. 2013 12/18;1(3):122-7.

10. Corp IB. Released 2013. IBM SPSS Statistics for Windows, Version 22.0. Armonk, NY: IBM Corp.

11.Yeoh C, Nixon JW, Dickson W, Kemp A, Sibert JR. Patterns of scald injuries. Archives of Disease in Childhood. 1994 1994-08-01 00:00:00;71:156-8.
12. Palmieri TL, Alderson TS, Ison D, O'Mara MS, Sharma R, Bubba A, et al. Pediatric soup scald burn injury: etiology and prevention. J Burn Care Res. 2008 Jan-Feb;29(1):114-8.

13. Rimmer RB, Weigand S, Foster $\mathrm{KN}$, Wadsworth MM, Jacober K, Matthews MR, et al. Scald burns in young children- a review of Arizona burn center pediatric patients and a proposal for prevention in the Hispanic community. J Burn Care Res. 2008 Jul-Aug; 29 (4):595-605.

14. Delgado J, Ramírez-Cardich ME, Gilman RH, Lavarello R, Dahodwala N, Bazán A, et al. Risk factors for burns in children: crowding, poverty, and poor maternal education. Inj Prev. 2002 Mar; 8 (1): $38-41$.

15. Millan LS, Gemperli R, Tovo FM, Mendaçolli TJ, Gomez DS, Ferreira MC. Estudo-epidemiológico de queimadurasemcriançasaten didasem hospital terciárionacidade de São Paulo. Revista Brasileira de Cirurgia Plástica. 2012 2012;27(4):611-5.

16. Marashi SM, Sanaei-Zadeh H, Taghizadeh Behbahani A, Ayaz M, Akrami M. Paediatric burn injuries requiring hospitalization in Fars, Southern Iran. Ann Burns Fire Disasters. 2016 Dec; 29 (4): 245-8.

\section{How to cite this article?}

S Prabakaran. Profile of scald injury among Paediatrics patient attending tertiary care hospital. Int J Pediatr Res.2018; 5 (7) : 362-367.doi:10.17511/ijpr.2018.i07.04. 